\title{
Buriwn $\mathfrak{n} \mathfrak{t}$.
}

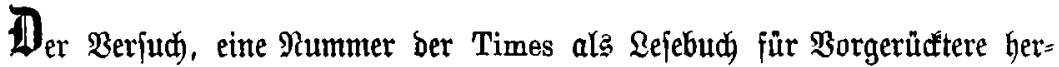

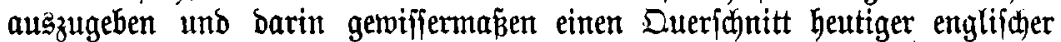

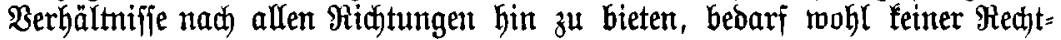
fertigung. Sas Bud, wie es num vorliegt, ift zumädjit für foldfe beredjet, meldhe mit bem grammatifjen Unterridyt unferer höheren Sajulen ziemlida ab= gefidlofien Gaben; ihnen foul es ein Mittel bieten, einen vollen Griff in bie

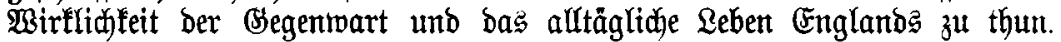

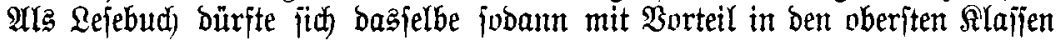

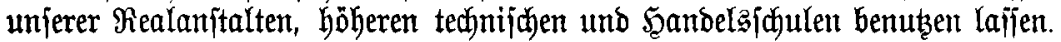

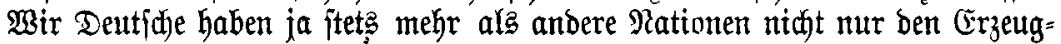

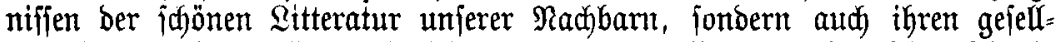

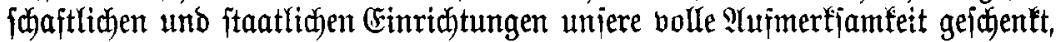

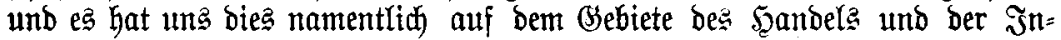

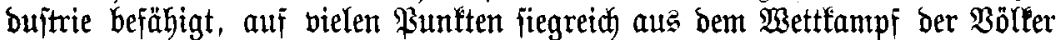
herborzugehen. atber audy bie moberne Bhilologie ift badurd gežbungen worben, bie Reafien nidft mehr in ber $\mathfrak{B s e i j e ~ a u p e r ~ a d j t ~ z u ~ l a f f e n , ~ w i e ~ b i e s ~}$ früher geffiah.

(53 ift eine befannte Thatjadje, baj ber Deutidhe, ber nad) (Sngland

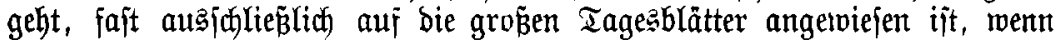
er fid) über (sinnidutungen, Sitten uno Bbebräutuje ber (Engländer unterridten will. Meil eben bie grop̉en 3eitungen twie bie Times, Daily News, Morning Post, ber Standard und Daily Telegraph Durch Pieidjhaltigfeit des Snhaltes

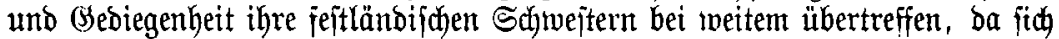

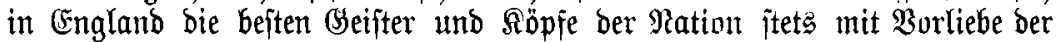
Breffe zugelwandt haben, hat jï bie Tagespreffe mehr als bei unz zul einer

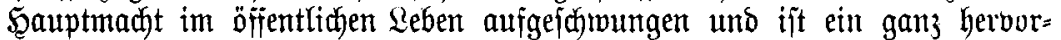
ragendes Element ber engliident Sultur gemorden.

Die $1 \mathfrak{B a h l}$ ber 3 eitung fonnte mir nidjt idjwer fallent. Tie Times nimmt unbejtritten bie erite Gtelle unter affen Beitungen ein, fo bẩ ein Eng= länoer mit Stolz bon ihr fagen fonnte: 'Wäare ganz Cinglanto bis auf

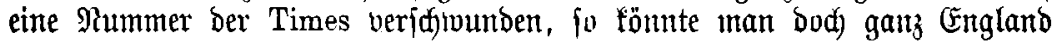
twieber aus biejer aufbauen.' Bei ber $\mathfrak{B a b l}$ einer Siummer - eine $\mathfrak{A} u s=$ 


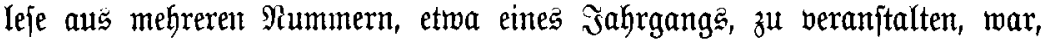
als nidgt bon ber Times geftattet, ausgefoflojien - ijt mir ber Bsefichts=

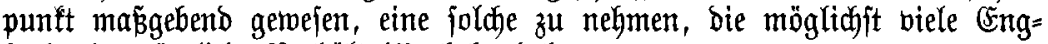
land eigentümliçe $\mathfrak{B} e r \mathfrak{b a ̈ l t n i f f e ~ b e h a n d e l t . ~}$

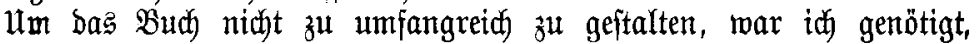
tweit über ein Drittel bez $\mathfrak{S n h a l t s}$ ber $\mathfrak{R}$ r. 31,725 vom 5 . April 1886

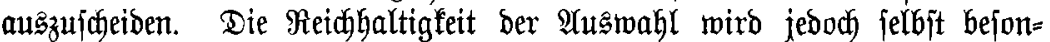

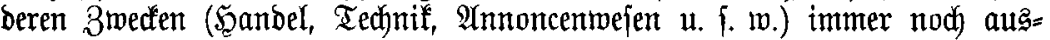

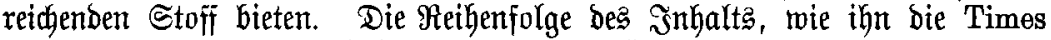

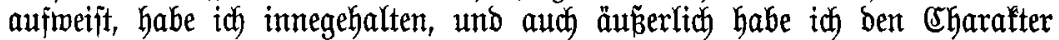
ber Zeitung wieberzugeben gejutht. Durchaus vermieden twurbe bie vielfach in ber Times angetwanbte fleine Sdifift; bod find veridfiebene Sabriften ber= mand, um bie in ber Times gemadyten $\mathfrak{u n t e r}$ (d)eidungen im Drudt ebenfalls lenntlid zu madhen.

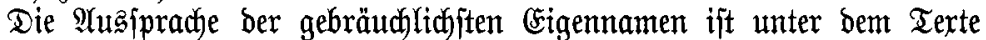

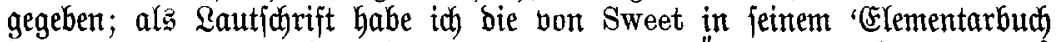

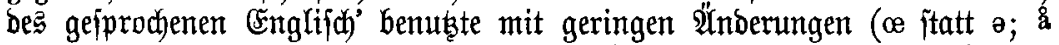

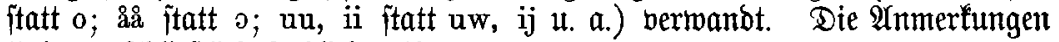

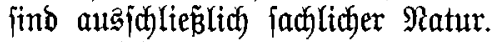

Bei ber $\mathfrak{A b}$ fajintug ber $\mathfrak{A n m e r f u n g e n ~ b i n ~ i d ~ v o n ~ v e r i c h i e s e n e n ~ S e t t e n ~ i n ~}$ ber liebenswürbigiten $\mathfrak{W}$ seife unterftübzt morben. $3 \mathfrak{u}$ ganz befonberem Danfe aber bin ich meinem Freunde Findlay Muirhead M.A. in Sondon ver= pflichtet, Der herborragend als Meitarbeiter beteiliat ift; er hat nidft alfein bie Anmerfungen bor bem Dond einer genauen $\mathfrak{P r u ̈ f u n g}$ unternorfen, fondern aud vieles in Deutichland nidht Fejtzuftellentoe oft mit groperer Mithe auf= geflärt; auperbem war er mir bei ber Durdfficht ber Drudtbogen befilffich.

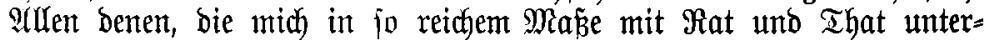
Ftüb̧ten, Freunden und Fad)leuten in Deutidjland, (England und 2 merifa, bor allem aber meinem Soerm Berleger, ber bas Bud mit bejonderer Riebe geförbert, jage id meinen bejten Danf.

Leipzig, im September 1888.

Dr. friedrid $\mathfrak{A} \mathfrak{a} \mathfrak{n} \boldsymbol{m} m \mathfrak{m} \mathfrak{u t}$. 